\title{
Significado extendido de la metáfora: aproximación e interpretaciones en fragmentos discursivos sobre éxito y fracaso en adultos mayores de Colima, México
}

\author{
Alan Emmanuel Pérez Barajas* \\ UNIVERSIDAD DE COLIMA
}

Desde un enfoque del discurso sociocultural a partir de entrevistas narrativas, este texto explora el papel de la metáfora como elemento de microsignificación en conjuntos discursivos verbalizados sobre éxito y fracaso por adultos mayores. El trabajo muestra cómo la metáfora, al ser un elemento lingüísticodiscursivo, licencia y ayuda a configurar el análisis semántico-cognitivo del discurso a partir de macroproposiciones que forman significados globales o macroestructuras semánticas que comúnmente no suelen ser consideradas como elementos primordiales.

(Discurso, metáfora, enfoque sociocultural de la lingüística, macroestructura semántica o significado global, elementos lingüístico-discursivos, éxito y fracaso, adultos mayores)

\section{El ESCENARIO}

¿Pa' qué te cuento de mis yerros?

Fracasé cuando anduve suelta y no me supe alzar.

A sí contestó doña Lucía Larios Torres el día 28 de marzo de 2009 cuando se le invitó a que contara sobre las experiencias buenas y malas que había tenido en su vida. Doña Lucy -como se le siguió nombrando durante los casi 45 minutos que duró su relato narrativo- había vivido en el asilo del municipio de Tecomán, Colima, desde hacía ya 5 años, cuando por voluntad propia y al verse sin familiares cercanos, decidió acudir con las hermanas de religión que cuidan el recinto ubicado en la finca marcada

*actante78@hotmail.com 
con el número 345 de la calle 2 de abril de Tecomán, Colima, acto seguido, cuando se le preguntó sobre su lugar de nacimiento y cómo fue que había llegado al asilo, ella respondió lo siguiente:

\section{Fragmento discursivo 1}

$[\mathrm{N}]$ o te digo que soy la mayor de cinco hermanas. Puritas hembras toditas y nací aquí merito en Tecomán, quedé güérfana cuando tenía ya, o lo verás, pos como unos trece años porque ya 'taba espigadita, he de ber andado pisándole o en las vísperas de los quince. Desde que mi mamá la recogió el de arriba, nomás a puro sufrirle con mi padre y andar diaquí pa' allá y ya pos, como uno no tuvo criaturas ni quien vea por uno, ya cuando no pude hacerme de centavos ni estar buenisana mejor me recogí aquí y, ¿pa' qué te cuento de mis yerros? Fracasé cuando anduve suelta y no me supe alzar (Lucía Alcaraz Torres, 87 años, Asilo de Tecomán, Colima.)

Ella, junto con otras once mujeres y doce varones de municipios urbanos y rurales de Colima, fueron entrevistados entre los meses de abril y diciembre de 2009. En cada uno de los relatos narrativos, existen contextos discursivos ${ }^{1}$ así como macroproposiciones ${ }^{2}$ que contienen metáforas relativas al éxito y al fracaso experimentado por los adultos mayores. La función de la metáfora como elemento lingüístico discursivo en estas narraciones es la de licenciar significados exten$\operatorname{didos}^{3}$ que configuran el habla de los adultos mayores. En el presente

${ }^{1}$ Se remite a una definición reelaborada a partir de la proporcionada por el diccionario de términos clave de ELE en Centro Virtual Cervantes en la siguiente liga: http://cvc.cervantes.es/ensenanza/biblioteca_ele/diccio_ele/diccionario/contextodiscursivo.htm El contexto discursivo es el conjunto de elementos que configuran la producción de un enunciado como su significado. Comprende un conjunto amplio y complejo de elementos, desde las circunstancias de espacio y tiempo en las que tiene lugar el evento comunicativo hasta las características, expectativas, creencias, intenciones y conocimientos de los enunciantes.

${ }^{2}$ Son declaraciones que los usuarios de la lengua hacen mediante la comprensión y producción del discurso, y también, organizan mentalmente los significados globales. Es decir, son los componentes principales a partir de los cuales se forman las macroestructuras semánticas o significados globales. Véanse las definiciones dadas por Van Dijk (2003) para una mejor comprensión de las macroproposiciones y su uso en el ACD.

${ }^{3}$ Se entiende por significados extendidos aquellos que no son directos sino que surgen de manera subyacente en los fragmentos discursivos. Típicamente licencian y dan sentido al conjunto de macroproposiciones o apoyan la comprensión global de un mapa temático del discurso. 
texto se evidencia cómo los adultos mayores se refieren al éxito y el fracaso como dos categorías atemporales, es decir, están siempre presentes a lo largo de sus vidas, o bien, en momentos o situaciones específicas en las que experimentaron triunfos o fracasos; emociones positivas o negativas; actitudes buenas y malas; pérdidas o ganancias.

El texto, entonces, explora cómo los adultos mayores configuran sus narraciones de éxito y fracaso a través de formas lingüístico-discursivas en entrevistas narrativas analizadas desde un marco interpretativo de la lingüística sociocultural propuesta por Mary Bucholtz y Kira Hall (2005) y el análisis del discurso de Teun Van Dijk (1996). La lingüística sociocultural engloba subcampos disciplinarios diversos como la sociolingüística, la antropología lingüística, el análisis conversacional, el análisis crítico del discurso y la psicología social con enfoque lingüístico (Bucholtz y Hall 2005, 586). "[A]mplio campo interdisciplinario interesado en la intersección entre lengua, cultura y sociedad” es su definición (p. 586). ${ }^{4}$ “[CC]ómo ilumina el estudio empírico de la lengua los procesos sociales y culturales?” es su pregunta clave $(2008,405) .{ }^{5}$ A partir de lo anterior, la pregunta que rige la investigación plasmada en este artículo es: ¿Cómo las metáforas en su calidad de microsignificados llegan a configurar significados globales en el discurso? Por consiguiente, el objetivo que se pretende es evidenciar la manera en que las metáforas llegan a conformar significados globales en las entrevistas narrativas.

Por entrevista narrativa entendemos una "narración biográfica amplia” en la cual se pide al informante que presente la historia de un área de interés en la que participó y, así, hacer evidentes procesos basados en hechos y revelar el 'cómo fue realmente"' (Flick 2002/2007, 114, 124; Hermanns 1995 apud Flick 2002/2007, 124).

Además de esta introducción y la conclusión, integran el texto tres partes. Primero se esbozan algunos referentes teóricos y conceptuales de la metáfora para el contexto de la metáfora en su génesis discursiva. Enseguida se detalla cómo se realizó la entrevista narrativa.

4 "[T] he broad interdisciplinary field concerned with the intersection of language, culture, and society".

5 " $[\mathrm{H}]$ ow does the empirical study of language illuminate social and cultural processes?". 
Después se presentan y analizan cómo las metáforas referidas al éxito y al fracaso configuran significados extendidos en las macroproposiciones y macroestructuras semánticas del discurso.

Otro punto importante en este trabajo es el de la significación del discurso y sus componentes. A continuación se transcribe en palabras de Van Dijk (2003, 146): “Discurso' se utiliza en el amplio sentido de 'acontecimiento comunicativo', lo que incluye la interacción conversacional, los textos escritos y también los gestos asociados [...], las imágenes y cualquier otra dimensión o significación 'semiótica' o multimedia'.

Entre los distintos modos de producción del discurso, podemos considerar al discurso oral como uno de los más efectivos en términos de simplicidad y rapidez. Desde el momento en que adquirimos las primeras nociones avanzadas del lenguaje, hasta que nos convertimos en emisores del discurso a plenitud, nos valemos mayormente de la oralidad para la expresión de ideas.

Para expresar ideas, por lo menos en un orden coherente y de manera contextual, los seres humanos empleamos, según Van Dijk (2003, 152), los temas (también conocidos como macroestructuras semánticas), que en términos generales incluyen la información más importante de nuestro discurso y "explican la coherencia general de los textos y las conversaciones".

Los temas son el significado global que los usuarios de una lengua establecen mediante la producción de y la comprensión de discursos, y representan la "esencia" de lo que más especialmente sugieren. Los usuarios de una lengua no son capaces de memorizar y manejar todos los detalles del significado de un discurso y, por lo tanto, organizan mentalmente estos significados mediante significados o temas globales. Definidos como significados globales, "los temas no pueden ser observados directamente como tales, sino que han de ser inferidos del discurso, o asignados a él, por los usuarios de una lengua”.

$\mathrm{Al}$ partir de los temas como guías en el discurso, también es posible resumir el discurso en macroproposiciones. ${ }^{6}$ Éstas no sólo resu-

${ }^{6}$ En el apartado correspondiente al análisis del corpus se observa el funcionamiento y empleo de las macroproposiciones como estructuras discursivas abstractas que resumen lo dicho mediante los temas en el discurso. 
men el discurso expresando partes del tema, representan también principios abstractos del discurso que se obtienen mediante inferencias. Dichas macroproposiciones pueden ser tomadas como representaciones socialmente compartidas por un grupo de hablantes, para este estudio, el significado de éxito y fracaso en el discurso cotidiano de los adultos mayores.

\section{REFERENTES TEÓRICOS Y CONCEPTUALES SOBRE LAS METÁFORAS}

[Y] 'ora ¿qué? Yo aquí guardada en mi casa con mis penas y él allá arriba.

Para este trabajo, se parte de la idea propuesta por (Bucholtz y Hall 2005) acerca de que el rasgo o aspecto sociocultural de la lengua " $[S]$ e construye por medio de una variedad de mecanismos semánticos y retóricos, uno de los cuales es el uso característico de la metáfora", esta última trasciende como parte de la imaginería y representaciones útiles de pensar e interpretar los discursos de los adultos mayores. Véase el siguiente fragmento discursivo verbalizado por Ana María Rosa Bravo Quintero cuando se le preguntó acerca de los momentos y situaciones que más recordaba como buenos o bonitos en su vida. Ella, hizo referencia a su padre de la siguiente manera:

Fragmento discursivo 2

[S]í [...] era también muy bragado y duro pa’ decir las cosas y de ese modo lo entendimos, que a lo mejor si nos haiga hablado suavecito ni lo hubiéramos entendido edá, porque él siempre nos quería vernos arriba. Él, él siempre fue, fue el pilar, el sostén, anque no fuera económico si tú quieres, pero él era el que sabía darnos palabras de aliento, el que daba el ánimo, el que nos mantenía en pié [...] siempre sacaba lo bueno que necitabanos y 'ora ¿qué? Yo aquí guardada en mi casa con mis penas y él allá arriba (Ana María Rosa Bravo Quintero, 67 años, Cerro de Ortega, Colima).

Como se puede apreciar en el fragmento anterior, las metáforas presentes en el discurso de los adultos mayores constituyen un uso 
figurativo de la lengua, se presenta como un rasgo generalizado en una cultura, en un grupo de hablantes o en una comunidad determinada como recurso discursivo que se logra por medio de la comparación o la analogía. En su forma más simple o sencilla, una metáfora es un mecanismo lingüístico discursivo de representación por medio del cual se comparte y aprende un significado. A partir de su configuración en el discurso cotidiano de los adultos mayores, las metáforas en contextos discursivos específicos, es decir, aquellos que han sido enunciados por detonadores discursivos, logran, como en muchos otros escenarios de producción, ilustrar los parecidos o diferencias de dos términos o marcos lingüísticos.

Una oración metafórica como la siguiente "Yo aquí guardada en mi casa con mis penas y él allá arriba" reduce dos términos a sus características comunes, permitiendo la transferencia lingüística del uno al otro. No hay que olvidar que también existen variaciones del tipo general de metáforas que sirven para ampliar su uso y análisis (apud Lakoff y Johonson 1980; Lodge 1977; Sapir 1977).

Para el propósito del análisis cualitativo en el presente artículo se debe considerar la metáfora en su contexto más amplio, es decir, en sus significados extendidos en los fragmentos discursivos de éxito y fracaso. En el análisis de los datos tomados de interacciones lingüísticas, se puede ocupar, no sólo de cómo se estructuran las metáforas, sino también de las maneras de cómo se usan y se comprenden. Lo anterior porque el empleo de las mismas en el discurso cotidiano cobra importancia para ejemplificar o hacer referencia a las relaciones personales, las costumbres, las formas de vida, las cosas buenas o malas que acontecen a las personas.

En el caso de la estructura narratológica de éxito y fracaso y su producción discursiva, el empleo de la metáfora no es únicamente un recurso del lenguaje sino que también es una estructura conceptual, de aquello que está en nuestro pensamiento y que expresamos con palabras. Podemos ver cómo la influencia de la metáfora en los adultos mayores, va más allá de la mera estética para trascender y presentarnos su visión del mundo que los rodea.

Si se retoma la idea de que la metáfora impregna no sólo el pensamiento sino también el lenguaje, se observa entonces que el sistema 
conceptual, es en gran medida también metafórico -se entienden la mayoría de los conceptos parcialmente en términos de otros- ya que los conceptos o ideas que rigen el pensamiento no son simplemente cuestión o parte del intelecto sino que rigen también la cotidianeidad. Muchas veces las metáforas son tan obvias o naturales para cada persona que, en los adultos mayores como en jóvenes y niños, se consideran descripciones directas y evidentes de fenómenos mentales. La mayoría de las personas pocas veces reparan en que son metáforas, pues se trata del modelo o esquema en que la mayoría de los hablantes piensan y actúan.

\section{LA DIMENSIÓN CONCEPTUAL DE LA METÁFORA EN EL DISCURSO}

$\mathrm{Al}$ retomar la postura sociocultural de este trabajo, con las metáforas del fragmento discursivo (vid supra) se puede quizás entender mejor lo propuesto por Sperber y Wilson (1994), en el que se da cuenta de cómo es que se producen los procesos de inferencia en un acontecimiento lingüístico, el desarrollo y la capacidad para relacionar y producir figuras retóricas (metáforas), entre otros elementos lingüísticos presentes en el discurso como muestra de enunciaciones que interpretan el pensamiento de los hablantes. El adulto mayor como sujeto enunciante en este trabajo tiene la capacidad de recrear y asociar, a través del empleo de metáforas, situaciones prácticas y entendidas por los interlocutores por el simple hecho de compartir referentes comunes.

En este sentido, la producción y análisis del discurso desde la perspectiva sociocultural, tiene como cometido establecer relaciones que sustenten y expliquen el soporte del discurso a partir de la recurrencia metafórica y, así, entender su uso como síntesis de un esquema o idea compartida materializada por la capacidad humana para identificar y relacionar elementos comunes ( $c f r$. esquema discursivo núm. 1). Así, se puede responder a la pregunta ¿Qué se entiende por dimensión conceptual de la metáfora? En un discurso tan motivado por temas de la experiencia y cognición compartida como éxito y fracaso, se puede responder que se trata de " $[E] 1$ conjunto de estructuras metafóricas que poseemos por experiencias 
compartidas y que a partir de las cuales, la mayoría de los conceptos se entienden parcialmente en términos de otros conceptos" (Lakoff y Johnson 1980, 96). El sistema conceptual adquiere entonces su dimensión en el discurso, a partir de la interacción constante con el mundo y personas que nos rodean. Se trata de referentes conceptuales básicos y fundamentales.

Los principales candidatos a conceptos entendidos directamente son los conceptos espaciales simples como ARRIBA. Nuestro concepto espacial ARRIBA emerge de nuestra experiencia espacial. Tenemos cuerpos y nos mantenemos erectos... [E]l carácter central de la orientación ARRIBA-ABAJO en nuestros programas motores y nuestro funcionamiento cotidiano... [I] ncluye también DELANTE-DETRÁs, DENTRO-FUERA, CERCA-LEJOS, etcétera. Éstos son los conceptos relevantes en nuestro funcionamiento corporal cotidiano constante... [E]n otras palabras, la estructura de nuestros conceptos que emergen de esta forma son conceptos de los que vivimos de la manera más fundamental.

Para Van Dijk (1999) el enfoque sociocultural del discurso recupera bastante bien, tanto los elementos retóricos (metáforas, símiles, eufemismos, etcétera), como las estructuras globales del significado, modelos mentales, esquemas representacionales y que, junto con las condiciones socioculturales de producción del discurso, determinan e influencian directamente el significado. Lo hacen resaltar y a la vez, al ser compartido por los usuarios de la lengua, puede inferir y confirmar creencias sociales dentro del marco representacional del contexto. Lo anterior es entendido como referente axial para lograr relacionar, a partir de las interacciones lingüísticas, el proceso de producción y comprensión de los discursos.

En tal sentido, la metáfora conceptual, de la que hablan Lakoff y Johnson (1980), está conformada por estructuras subyacentes que no pueden dejarse a un lado ya que son imperativas en el denominado enfoque sociocultural del discurso, donde las metáforas conforman junto con otras estructuras retóricas y lingüísticas, las macroestructuras del discurso. Su análisis es fundamental para entender en contexto la interacción lingüística y el significado global que licencian. 
Como se puede apreciar, la dimensión de la metáfora en el plano conceptual es primordial en el entendimiento y comprensión de los significados que emergen de las macroestructuras y macroproposiciones del discurso. No se podría entender ni valorar todo lo que al análisis del discurso puede aportar, por ejemplo la metáfora conceptual, para mostrar y representar un esquema referencial, ${ }^{7}$ surgido a partir de la conceptualización por un detonador discursivo, que permita representar un significado global o temático.

Metodológicamente, el empleo del lenguaje metafórico en el discurso en los hablantes añosos representa una oportunidad única para la metodología empleada en este trabajo (la entrevista narrativa, cuyas características y operatividad se explicarán en párrafos subsecuentes) ya que ilustra la forma en que los adultos mayores, en este caso, usan la lengua para expresar significados y experiencias atemporales y particulares. La incorporación de la metáfora como elemento que licencia un esquema referencial en el discurso, abona bastante en la comprensión global de una macroestructura semántica. Lo anterior, toda vez que el análisis de planos conceptuales discursivos puede hacerse a partir de la configuración del discurso con el empleo de metáforas distintas, de modo que a partir de ello se logre representar no sólo significados globales, temas metafóricos, macroestructuras temáticas o conjuntos discursivos configurados a partir de elementos o figuras retóricas, sino también examinar datos cualitativos que dejen entrever a percepción, los esquemas representacionales, ideologías, significados individuales y las propias experiencias particulares (apudDenzin 1987; Fieldman 1994). Así, la insistencia de incluir la metáfora en el análisis de planos conceptuales en el discurso, apuesta a una eficaz identificación de significados globales y su representación. Este modo de análisis, por así decirlo, implica un cúmulo de conocimientos tanto teóricos como metodológicos sobre la teoría general de la metáfora y por supuesto, compromisos metodológicos para poder generar narraciones, a partir de detonadores discursivos: “ [U]n modo de análisis que busca

${ }^{7}$ Es la representación gráfico-verbal que muestra los elementos tanto gramaticales como discursivos en un ejercicio específico de verbalización. 
comprender cómo las metáforas actúan y transmiten un significado del contexto" (Coffey y Atkinson 2003, 99).

\section{LA METÁFORA Y SU REPRESENTACIÓN SEMÁNTICO COGNITIVA}

Para entender cuál es el significado y la representación cognitiva que encierra la metáfora en el discurso cotidiano es necesario considerar que en una producción discursiva ya sea con un enfoque metodológico estrictamente de $\mathrm{ACD}^{8}$ o sociocultural, es importante compartir que por cognición podemos entender lo que señala Varela et al. (1991) " $[\mathrm{N}]$ o es la representación de un mundo previo por una mente previa, sino la escenificación de un mundo y de una mente sobre la base de una historia de acciones que realiza un individuo en el mundo".

La función de la metáfora en el discurso está referida, entonces, al plano de las experiencias. Lakoff (1986) postula integrar en el concepto de "experiencia" las experiencias básicas sensoromotrices y emocionales igual que las de carácter social, que en palabras de este autor, son un funcionamiento activo y una motivación de lo que realmente es significativo en el pensamiento humano. La experiencia, señala Lakoff, hace posible la comprensión conceptual así como pone límites al rango de estructuras racionales posibles. Desde esta postura, las estructuras de significado, como su representación, tienen su origen en la naturaleza estructurada de la experiencia corporal y social; y de la capacidad que se tiene para proyectar imaginariamente la experiencia corporal y de interacción con otro tipo de estructuras de significado más complejas o abstractas.

Esta "proyección conceptual" que incluye mecanismos como la metáfora en contexto del discurso motivado está fuertemente fijada no sólo en la experiencia corpórea sino también social. La metáfora cobra su utilidad y necesario análisis como parte de las microproposiciones del discurso ya que ayuda a detectar las conceptualizaciones subyacentes y poder formular relaciones de significados no directos sino más bien extendidos.

\footnotetext{
${ }^{8}$ Análisis crítico del discurso desde la propuesta de Van Dijk, 1998.
} 


\section{METÁFORA Y MACROESTRUCTURA SEMÁNTICA}

Las metáforas se presentan en el discurso, tanto como parte de un continuum, así como de la bidireccionalidad y redireccionalidad. Ambos, son términos empleados por Contoursi y Ferro (2000) como parte de los elementos y herramientas de la narración. Se trata de dos condiciones que se deben cuidar en las entrevistas narrativas. El primero tiene como propósito acompañar al narrador a lo largo de la verbalización y cuidar el eje temático de la producción discursiva; el segundo, volver a sucesos o episodios narrados que requieran una verbalización más profunda o resolución necesaria. En ambos, la metáfora se presenta como portadora de un significado en la estructura narrativa y elemento de cambios, sucesos, acciones y estados; sirve al narrador como referente preexistente de su producción lingüística frente a su experiencia ya que su enunciación no está supeditada a que la narración se produzca con referencia al presente: el informante va y viene con toda comodidad en el tiempo y espacio verbales (Meyer 2007).

Las metáforas llegan a establecer relaciones o conexiones en una macroproposición como parte de un dominio conceptual; estas son en palabras de Lakoff (1986) como "La correspondencia o ámbito de experiencias que posee un nivel cognitivo que es posible delimitarlo en relación con otros". Se trata de dominios de experiencia, por ejemplo, relaciones sentimentales, economía, efectos, emociones, actitudes, éxito y fracaso, etcétera. Así, el significado que provee la metáfora a una macroproposición está en la proyección de un dominio de experiencias sobre otro. Este proceso puede ser observado en la producción discursiva en términos de correspondencias metafóricas establecidas entre distintos dominios que llegan a conformar una red externada en un conjunto discursivo provisto de significados entendidos (apud Lakoff y Johnson 1980, 96-98).

La función semántica de la metáfora en el contexto de producción del discurso a partir de dominios requiere contestar las siguientes dos preguntas ¿Qué se entiende por función semántica? y ¿qué es la producción discursiva a partir de dominios? Para dar respuesta a 
lo anterior es importante precisar que se trata de un ejercicio heurístico desde el análisis sociocultural donde la metáfora es elemento clave en la configuración del discurso. Por función semántica se entiende la interpretación que de los dominios léxicos hacen los usuarios de la lengua en diferentes planos; ello permite poner en manifiesto el nivel microsemántico y las operaciones conceptuales que se hacen de un plano al otro. Por producción discursiva a partir de dominios, deberá considerarse como los actos de verbalización específicos auspiciados por detonadores del discurso (éxito y fracaso para efectos de este texto) que a partir de las nociones de sentido literal, metafórico y derivado son generados en el discurso ( $c f r$. François Rastier 2005, 14-16).

Lo antes expuesto ayuda a entender que el análisis semántico cognitivo de las metáforas en contextos discursivos particulares se basa y cobra riqueza en la importancia cultural de los símbolos lingüísticos para crear y mantener significados compartidos. La importancia de esta postura radica en la concepción de que los hablantes, como actores sociales, ordenan sus experiencias por medio de referencias simbólicas que no se limitan al uso lingüístico y pueden incluir eventos y experiencias tanto individuales como compartidas sin requerir de un saber sofisticado. Tal como lo señala Spradley (1979) se trata de la comprensión de tareas diferentes pero identificadas por quienes las emplean. Por ejemplo, por anciano se hace referencia como símbolo lingüístico al varón o mujer que ha cumplido una determinada edad y que ante todo posee características físicas y mentales específicas y bien identificadas por quienes lo refieren, pero a la par, o de modo subyacente, existen denominaciones que son asociadas con elementos o características de otros referentes, pero que como símbolos o códigos simbólicos se dan por sentados y entendidos dentro de un determinado contexto cultural ya que llevan implícita una concepción compartida: anciano es igual a persona de avanzada edad, alguien entrado en edad, un hombre o mujer en el invierno de su vida, un sujeto en el ocaso de la vida, etcétera.

Así, la metáfora como elemento discursivo en el uso cotidiano de la lengua, forma parte de microproposiciones y éstas a su vez 
conforman macroproposiciones que configuran los significados globales o macrostructuras semánticas en el discurso. Lo anterior, en términos de Van Dijk (2003) se entiende como los elementos que conforman la noción de tema. Es pues el empleo de tales términos los que ayudan a entender las propiedades del significado o del contenido específico y a la vez global del discurso en contexto.

\section{Metodología: un EJERCiCio DE CAMPO CON HABLANTES ENTRADOS EN AÑOS}

“¿[Y] 'ora qué hago? Si ya uno entrado en años nomás 'ta uno marchito; pues no le queda a uno diotra. Nomás esperar que Dios nos recoja con bien" (Martín Lucatero Cárdenas, 88 años, Asilo de Tecomán, Colima). Así verbalizó don Martín cuando se le preguntó qué hacía él en el asilo para vivir y sentirse bien. Su discurso además de otorgar la posibilidad de analizar la metáfora conceptual de ser anciano en función de lo que puede o no hacer por la edad, brinda la posibilidad de estudiar otros aspectos desde el análisis del discurso sociocultural como la emergencia y la indexicalización de la identidad. Ambos, aspectos importantes en el nombramiento y comprensión del discurso.

El levantamiento de la información se realizó a partir de la técnica de la entrevista narrativa, se implementó a partir de detonadores discursivos y se desprenden de un corpus de 24 entrevistas realizadas en barrios populares de municipios urbanos y rurales de Colima con doce varones y doce mujeres que se ajustaron al perfil del siguiente caso típico ideal: mayores de sesenta años, lúcidos y originarios de Colima o con más de veinte años de residencia. Ese corpus, a su vez, forma parte de otro mayor de cincuenta entrevistas narrativas recolectadas en cuatro municipios urbanos y cuatro rurales del estado de Colima. Sobre estos materiales descansa el proyecto "Grandes testimonios: verbalización del éxito y el fracaso en adultos mayores de Colima”, financiado en 2009 por el fondo Ramón Álvarez-Buylla de Aldana de la Universidad de Colima y apoyado por estudiantes del sexto semestre de la licenciatura en lingüística de la Facultad de Letras y Comunicación de la misma universidad. 
Las entrevistas fueron audiograbadas en formato digital y transcritas como una transcripción ortográfica verbatim en formato vertical con puntuación convencional e indicaciones paralingüísticas -silencios, risas, llanto-. Su duración es de 69 minutos. Los informantes cuyos nombres aparecen aquí, dieron su consentimiento para ser grabados y usar su nombre verdadero.

Las entrevistas narrativas adoptaron la secuencia sugerida por Uwe Flick: pregunta generadora de narración o detonador discursivo, estadio de preguntas de narración y fase de balance (2002/2007, 111-112). Arrancamos con una pregunta generadora de narración, detonador discursivo que activa la memoria de los informantes "encaminándola hacia la narrativa personal que permite verbalizar y situar una experiencia en un discurso, en el que el sujeto se representa subjetivamente" (Meyer 2007, 79).

\section{Algunos ejemplos de Metáforas de ÉXito y FRACASO EN EL DISCURSO DE ADULTOS MAYORES}

\section{Por el paso de los años, el cuerpo esta frío y desgastado}

Fragmento discursivo 3

“[A] estas alturas de la vida uno nomás espera el final porque por el paso de los años, el cuerpo está frío y desgastado y que no me den santa sepultura sería otro hundimiento en mi vida" (Lucía Alcaraz Torres, 87 años, Asilo de Tecomán, Colima).

Esta fue la respuesta que brindó dońa Lucía cuando casi al fin de la entrevista se redireccionó con la siguiente pregunta: Entrevistador (Alan): Usted me mencionó que no le quedaba más que esperar porque siente ya mucho cansado su cuerpo ¿Qué es lo que espera dońa Lucy? Entrevistada (Lucía): "[U]no nomás espera el final porque por el paso de los ańos el cuerpo está frío y desgastado".

En el contexto discursivo anterior los dominios de cuerpo en relación a lo frío, el desgaste y el hundirse, no sólo denotan empleo metafórico en la configuración de la macroestructura semántica sino que dejan entrever la superposición de estos tres elementos con 
la trayectoria de la vida comparada con un camino, el camino que cada quien sigue en la vida misma. Se rescata la noción de cuerpo y sus condiciones de estar "frío" y "desgastado" como planos característicos relacionados con el fracaso. La vida es un camino, los años parte de la trayectoria y la imposibilidad del cuerpo, las características o la manera en que se manifiesta el transcurrir del tiempo.

A continuación se presentan ejemplos de las metáforas que configuran el discurso de los adultos mayores. Su análisis no va más allá de lo que este trabajo pretende mostrar de acuerdo con su objetivo inicial: evidenciar cómo los adultos mayores configuran sus narraciones de éxito y fracaso a través de metáforas como formas lingüístico-discursivas en su narrativa cotidiana. El análisis no pretende ir al interior de las macroclases o clases de metáforas, sino analizar la función de la metáfora desde un marco interpretativo de la lingüística sociocultural para la comprensión de significados globales y extendidos.

En términos del análisis de los datos, las metáforas pueden considerarse en gran número de formas diferentes en la configuración del discurso en personas añosas. Por ejemplo, constituyen estructuras explicativas de la macroestructura semántica; expresan similitudes en los dominios de las mismas; organizan estructuras discursivas subyacentes; sirven para dar sentido u organizar, en relación con significado global, las percepciones de los ancianos; van más allá de conjeturas y la mera exclusión. A continuación, como parte de este análisis, se presentan ejemplos de cada uno de estos casos en un cuadro o esquema clasificatorio en atención al formato de sistematización que se siguió para su análisis. En cada caso, la primera columna hace referencia al significado global o macroestructura semántica; la segunda a la macroproposición, que no es sino el fragmento discursivo en contexto donde radican los elementos lingüísticos discursivos y, finalmente, la microproposición conformada por la correspondiente metáfora (véanse ejemplos de conjuntos discursivos 1 y 2).

A) Muchas metáforas que sustentan macroestructuras semánticas como elementos lingüístico-discursivos, trasladan estructuras explicativas de un dominio familiar de experiencias a otro dominio ante la necesidad de su comprensión o explicación (Klaus Krippendorff 1997, 110). 


\section{Conjunto discursivo 1. Elementos que integran la macroestructura semántica de fracaso}

MACROESTRUCTURA MACROPROPOSICIONES MICROSIGNIFICADOS

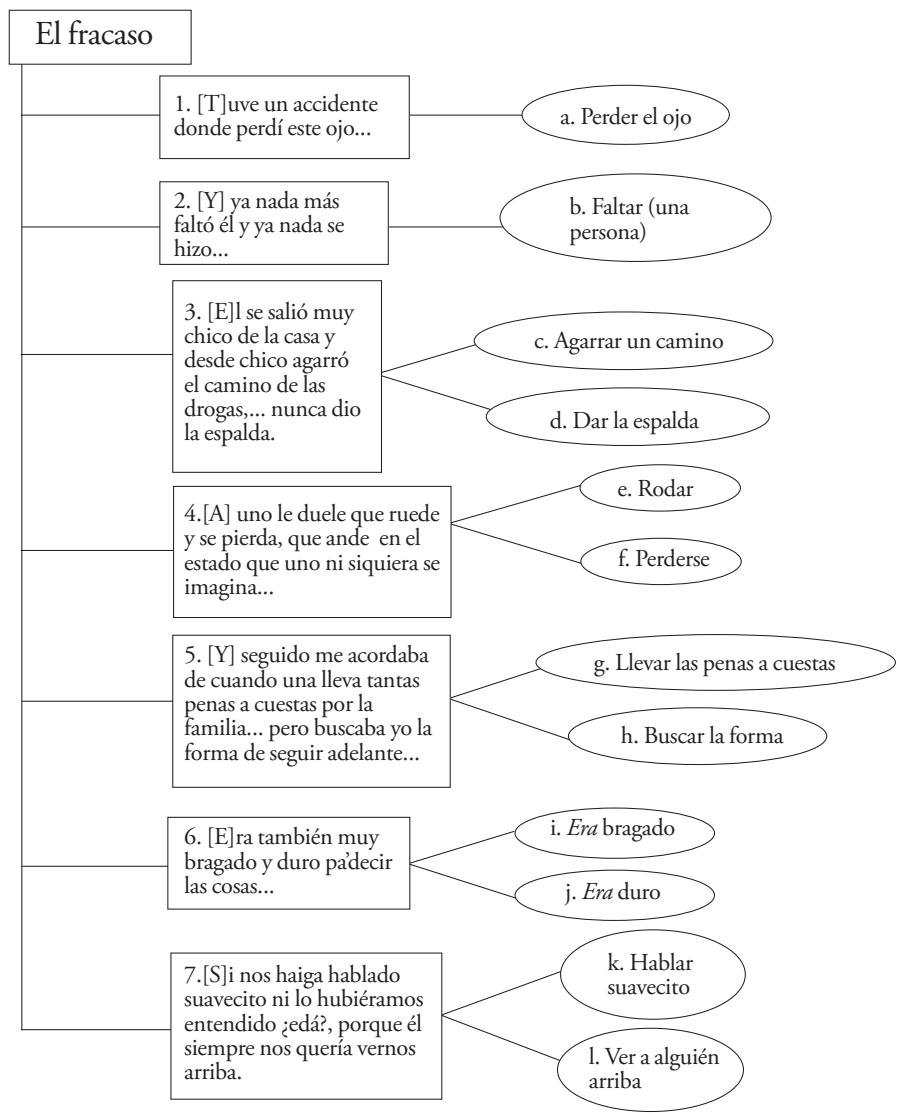

Como se puede apreciar en el esquema anterior, las metáforas que licencian las macroproposiciones, nos dan elementos semánticos para proponer el tema general del discurso, sin que sea éste, necesariamente un ejercicio o propuesta conceptual irreductible. Así, pudiésemos enunciar que a la macroestructura semántica de fracaso en los adultos mayores, en este caso, le corresponden los temas de 
AUSENCIA, PÉRDIDA, BÚSQUEDA Y DESCONTROL (véanse las metáforas 1.a; 2.b; 3.d; 4.f; 5 h y 7.l) El caso del verbo ser en tiempo pasado da cuenta, no sólo del tiempo verbal en que se enuncia el discurso, sino de la transmisión de un estado tangible (dureza) a un plano de actitud o forma de ser de una persona; se trata pues de apoyarnos en la función de la metáfora para entender que se establece una especie de traslado aparentemente sencillo por parte del hablante al atribuirle un estado o situación de un objeto o cosa (dureza) a una función particular (el habla). Es un proceso contrario a lo señalado por Johnson (1987) cuando establece que "[L]a cognición se apoya en el cuerpo, y que sin éste no es posible que funcione; y en el terreno del lenguaje, que las expresiones lingüísticas no son comprensibles sin tener en cuenta el papel del cuerpo".

B) Las metáforas -como las anteriores- en conjuntos discursivos disímiles ${ }^{9}$ por redireccionalidad o bidireccionalidad, requieren que se adviertan algunas similitudes estructurales entre los dos dominios. A veces, esa similitud o parecido reside en el uso de las palabras como el de las experiencias conceptualizadas por ellas. Se puede entonces hablar de una especie de enlaces de dominios en el discurso, pero significando en cada uno situaciones completamente diferentes. En la página siguiente se presenta un ejemplo con varios fragmentos discursivos.

Las metáforas que licencian la configuración de la macroestructura anterior aportan, como elementos de significación discursiva y no sólo retórica en el plano y género del discurso, elementos semánticos que llevan a proponer como tema o significado global la noción de MOVIMIENTO, CAMBIO DE SITUACIÓN Y MOVIMIENTO EN UN ESPACIO O TRAYECTORIA; y también la nOCiÓn de CORPOREIZACIÓN. Por ejemplo, si pensamos en términos de relaciones ESPACIO-CAMBIO-SITUACión, basta con observar las metáforas (1.a; 2.c, d; 3.f, g) en su respectivo fragmento discursivo. Por otra parte en las metáforas (1.b y 2.e) existe el elemento de corporeidad que sustenta la

${ }^{9}$ Se entiende como conjunto disímil de metáforas porque en el discurso cotidiano, producido por detonadores discursivos, las metáforas pueden aparecer como metáforas conceptuales o meras expresiones metafóricas. 


\section{Conjunto discursivo 2. Elementos que integran} la macroestructura semántica de éxito

\section{MACROESTRUCTURAS \\ MACROPROPOSICIONES MICROSIGNIFICADOS}

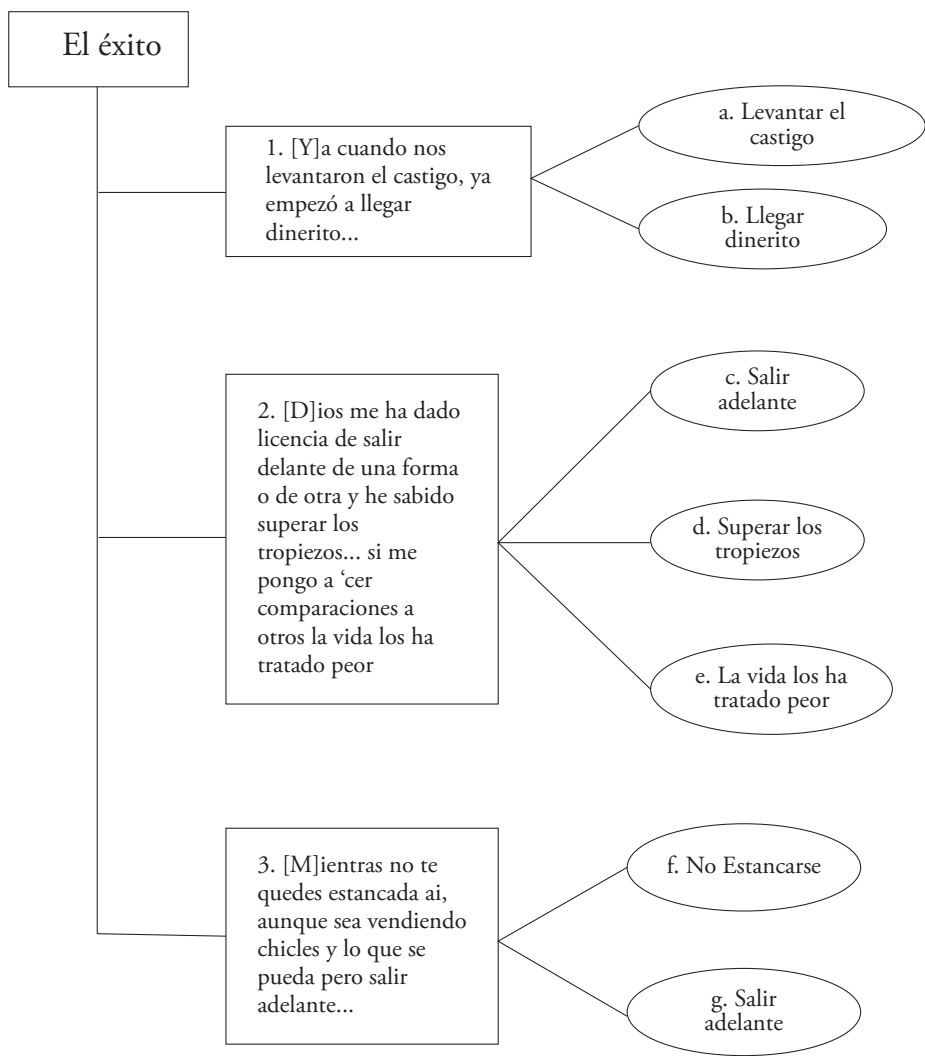

función metafórica. Esta función subyacente emerge gracias al contexto discursivo, es decir, la situación; y que además sirve para sustentar el tema de la macroestructura y conocer cómo se llega a representar la actividad cognitiva a partir de los atributos del cuerpo para representar situaciones y conocimientos cotidianos. 
Para sustentar lo anterior desde una mirada sociocultural del discurso pensemos por ejemplo en el siguiente enunciado propuesto por Bernárdez (2008) cuando dice que "[E]l cuerpo es también, sin duda, un objeto social y cultural”. Entonces tenemos que las metáforas con atributos de corporeidad o embodiment, establecen no sólo una obvia referencia al cuerpo sino que queda de manifiesto en el discurso temático (éxito o fracaso) como elementos microsignificativos que tienen su raíz en la posición, fuerza, dirección, sentimientos, bonanza y perdón, entre otros.

C) Las metáforas conllevan implicaciones (Lakoff y Johnson 1980) para el dominio de aplicación, ya que organizan estructuras discursivas subyacentes ajustando rasgos seleccionados en un patrón de similitud. Los siguientes ejemplos (de los fragmentos discursivos 4) presentan la interacción humana relacionada con el éxito y el fracaso como reacciones instantáneas de los adultos mayores involucrados; asimismo, las metáforas en el discurso se presentan como una experiencia fortuita e involuntaria en la que difícilmente se puede intervenir volitivamente. Véanse los siguientes fragmentos discursivos.

Fragmentos discursivos 4

1. "[S]alir adelante, más que nada es algo que lo empuja a uno pa' salir y hacer, porque quieres darles a tus hijos lo mejorcito..."

2. "[L]a suerte nos castigó porque no nos mandaba dinero mucho tiempo..."

3. "[Q]ue me ayudaran a lo que a mí me gustaba, a mí me llama mucho la medicina..."

4. "[L]o más triste que me ha pasado es la muerte de mi papá... me pesó mucho cuando él acabó...”

D) Las metáforas en el discurso de los adultos mayores -más los que pertenecen al ámbito rural- organizan las percepciones de los hablantes ancianos (véase fragmento discursivo 5) como podemos ver, se trata de afirmaciones metafóricas que en su propia emisión y sustento discursivo, puede crear o constituir el hecho que afirma, el 
cual resulta ser en este caso un fenómeno social. En la interacción humana, el dominio original o fuente (éxito) retrocede y se vuelve accesorio o secundario. Se niega y se atribuye a una causa determinada (Dios).

\section{Fragmento discursivo 5}

1. "No hay éxito, sólo hay cosas buenas y ésas nos las da la mano de Dios"

E) La metáfora en el discurso de los adultos mayores, no se reduce a los principios de exclusión y conjetura. Implica que se pueda dar una aproximación al significado en extenso del discurso y ése, va más allá del que se produce a través de la gramática del discurso, las estructuras semánticas de análisis (bajo cualquier modalidad) o el mismo lenguaje recto. La metáfora y su configuración en fragmentos discursivos coherentes de la lengua, como argumentos y relatos brindan la oportunidad de acercarse a la naturaleza sociocultural del significado en contextos específicos. ${ }^{10}$

La presencia de la metáfora en segmentos discursivos de éxito y fracaso en los adultos mayores permite ir más allá de los principios de exclusión y conjetura señalados por James P. Gee (2003). El principio de exclusión en el discurso establece que el significado de las palabras o frases proferidas o no bajo un mismo eje temático o campo semántico, depende en parte de los términos cuya posible aplicación en una situación determinada pretenda excluir la forma de usar y entender las palabras. El significado depende en gran medida de la función que posean los elementos lingüísticos discursivos en contexto. Es aquí donde la metáfora tiene un papel inclusivo.

En algún momento del discurso, las opciones de verbalización son limitadas o demasiado específicas; sus significados son directos

${ }^{10}$ Debe aclararse que, para efectos del análisis, por contextos especificos debe entenderse como el engarce entre personas adultas mayores y las condiciones que en su vida cotidiana influyen como determinantes de la verbalización del éxito y fracaso. Es decir, en su mayoría ancianos, en condiciones económicas desfavorables, socialización e integración no tan favorecida, con necesidades afectivas, pérdida de memoria, etcétera (cfr. Sánchez Salgado 2005). 
o precisos, mientras que el significado metafórico incluye significados extendidos a partir de dominios trasladados dentro de una misma macroestructura semántica. Obsérvese el anexo 1 como ejemplo de una macroestructura semántica de éxito donde las líneas continuas son significados directos y las discontinuas significados extendidos.

En este ejemplo se puede apreciar que el principio de exclusión implica que en el continuum del discurso normalmente los adultos mayores se refieran al éxito y fracaso pero en términos distintos a los de los significados de contexto directo; es aquí donde aplica el papel inclusivo de la metáfora.

Por lo que respecta al principio de conjetura en el discurso (P. Gee 2003, 89) lo refiere como un segundo principio fundamental del significado en discurso: "[S]ólo podemos hacer juicios acerca de lo que otros (y nosotros) entienden por una palabra utilizada en una determinada ocasión conjeturando cuales son las otras palabras o significados que excluyan o no la utilizada con independencia de lo convencionalizado o no, de lo consciente o inconsciente que pueda ser la conjetura”.

Mucho de lo que el discurso de los adultos mayores incluye y es entendido en contextos discursivos es posible gracias a la capacidad de poder emplear palabras o frases en términos de otras excluyendo términos inexactos o no directos pero también permitiendo en amplios márgenes "interpretar" lo que los demás entienden o quieren decir.

\section{DisCUSIÓN FINAL}

Como un elemento sociocultural del discurso cotidiano, la metáfora permitió la comprensión de diferentes facetas que integran la experiencia de vida de los adultos mayores; a través del análisis queda abierta la posibilidad de reflexionar y considerar la pertinencia de la metáfora como esclarecedora de significados globales a pesar de ser ya considerada como inherente al lenguaje por múltiples lingüistas y discursivistas, comenzando por Jakobson (1963), Lakoff y Johnson (1980), Searle ( 1980), Van Dijk (1987), Peirce (1987), Tomlin (1997), Chilton (1994) entre otros. 
Este trabajo muestra la relevancia del estudio de la metáfora en temáticas socioculturales, como es el caso de las concepciones del éxito y el fracaso en los adultos mayores, por ello no se puede ignorar la riqueza semántica de la metáfora como elemento del pensamiento en los adultos mayores, específicamente en lo que se refiere al éxito y fracaso en sus vidas, porque como se pudo apreciar, la metáfora configura en mucho el pensamiento que subyace a sus actos narrativos; de modo que, como lo precisa Van Dijk (2000), las macrocategorías en el discurso están determinadas por la triada discurso -cognición- sociedad por centrarse en aspectos culturales y antropológicos de la lengua.

En un intento por responder a la pregunta rectora de este trabajo ¿Cómo las metáforas en su calidad de microsignificados llegan a configurar significados globales en el discurso? se podría decir que tratándose de los estudios sobre el discurso y otros campos o subdisciplinas científicas, el estudio de la metáfora y el conocimiento en su configuración real, por lo menos en tópicos comunes como el éxito y fracaso, el estudio de la lengua ayuda a la comprensión global de los procesos de significación a partir de los cuales se da la interacción lingüística cotidiana en una sociedad contemporánea.

Para culminar, se sugiere la conveniencia de incorporar a la investigación en ciencias humanas un análisis inclusivo desde la teoría de la metáfora y las metodologías narrativas. 
Anexo i. Ejemplo gráfico de una macroestructura semántica de éxito que ejemplifica la construcción del significado directo y extendido por metáforas

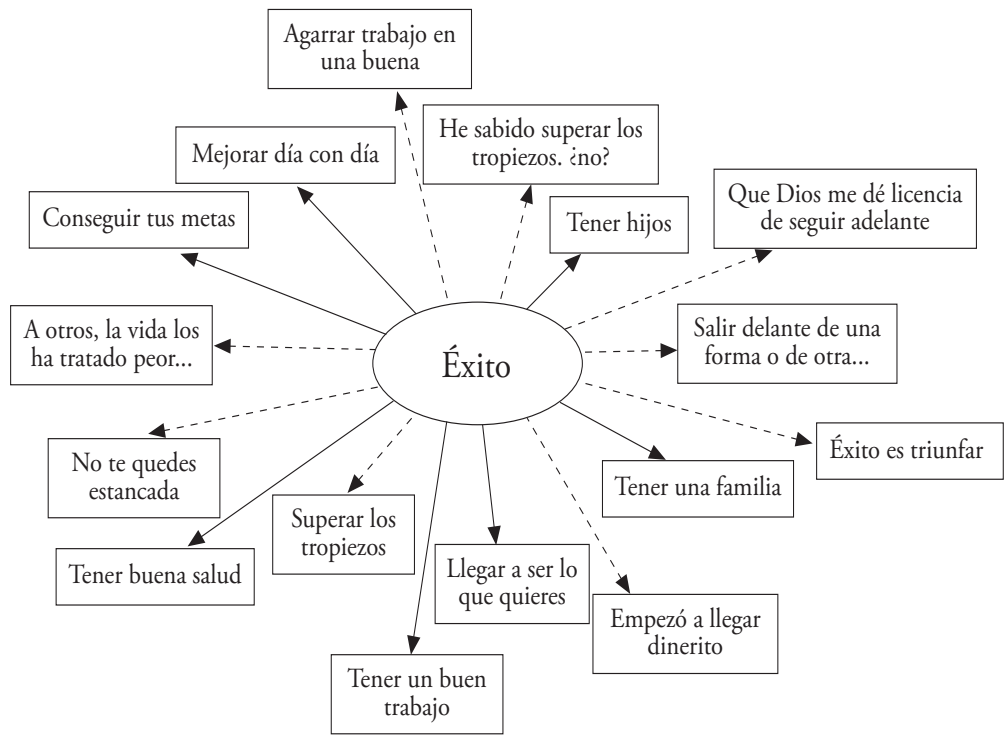

Fuente: Elaboración propia.

\section{BibLIOGRAFÍA}

Bernárdez, Enrique, El lenguaje como cultura, Madrid, Alianza editorial, 2008, 461-467.

Bucholtz, Mary y Kira Hall, Identity and interaction: A Sociocultural linguistic approach, Discourse Studies, 7/4-5, 585-614, 2005.

Coffey, Amanda y Paul AtKinson, Encontrar el sentido a los datos cualitativos, Antioquia, Universidad de Antioquia, 2003, 99127.

Contoursi, María Eugenia y Fabiola Ferro, "La narración. Usos y teorías", en La enciclopedia Latinoamericana de Sociocultura y Comunicación, Buenos Aires, Grupo Editorial Norma, 2000.

Chilton, Paul y Mihail Llyin, "Metaphor in Political Discourse: 
The Case of the Common European House", Discourse and Society, 4(1), 1-31, 1994.

DenzIn, Norman, On semiotics and symbolic interactionism. Symbolic interaction, 1987, 1-19.

Fieldman, Martha, Strategies for interpreting qualitative data, Thousand Oaks, Sage, 1994.

FuICK, Uwe, Introducción a la investigación cualitativa, Segunda edición, Trad. Tomás del Amo, Madrid, Coruña, Morata, Fundación Paideia Galiza [original en alemán, 2002], 2007.

GeE, James Paul, La ideología en los discursos, Madrid, Morata, 2005.

JaKobson, Roman, "Parts and wholes in language", en Linda R. Waugh y Monique Monville-Burston, eds., On Language, Cambridge, Londres, Harvard University Press, 1990, 110-114.

JoHnson, Mark, The body of the mind, Chicago, University of Chicago Press, 1987.

Krippendorff, Klaus, Principales metáforas de la comunicación y algunas reflexiones constructivistas acerca de su utilización, en M. Pakman, Construcciones de la experiencia humana. Barcelona, Gedisa, 1997.

Lakoff, George y Mark Johnson, Methapors we live by, Chicago, The Univesity of Chicago Press, traducción en español como Metáforas de la vida cotidiana, Madrid, Cátedra, 1980.

LAKOFF, George, Two metaphorical issues. Tthe meaning of literal, a figure of thought, Berkeley Cognitive Science Report núm. 38, 1986.

LoDGe, David, The modes of modern writing, Londres, Eduard Arnold, 1977.

MeYer, Michael, Análisis crítico del discurso, España, Anagrama, 2007.

Peirce, Charles Sanders, The Essential Peirce 2. The Peirce Edition Project, Bloomington, Indiana University Press, 1998.

Rastier, Francois, Semántica Interpretativa, México, Siglo XXI Editores, 2005.

Sánchez, Carmen Delia, Gerontología Social, México, Editorial Espacio, 2005. 
SAPIR, J. David, The anatomy of metaphor, en J. Sapir, J. C. Crocker, eds, The Social Use of Metaphor: Essays on the Anthropology of Rethoric, Filadelphia, University of Pennsylvania Press, 1977, 3-32. SEArle, John, Actos de habla, Cambridge, University Press, 1980. Sperber, Dan y Deirdre Wilson, La relevancia, Madrid,Visor, 1994.

Spradley, James, The ethnographic interview, Nueva York, Holt, Rinehart and Winston, 1979.

Tomlin, Russell, Linda Forest, Pug Ming Ming y Kim Myung HeE, "Semántica del Discurso", en Teun Van Dijk, ed., El discurso como estructura y proceso, vol. I, Barcelona, Gedisa, 2000, 107-170.

, Estructuras y funciones del discurso, México, Siglo XXI Editores, 1996, 115-142.

, La multidisciplinariedad del análisis crítico del discurso: un alegato en favor de la diversidad, en Métodos de análisis crítico del discurso, Barcelona, Gedisa, 2003.

, Ideología. Una aproximación multidisciplinaria, Barcelona, Gedisa, 1999.

, Ideología y discurso, Barcelona, Ariel, 2003, 146, 152.

VArela, Francisco, Evan Thомsom y Eleanor Rosh, The embodied mind. Cognitive Science and human experience, Cambridge, The MIT Press, 1991.

\section{BIBLIOGRAFÍA EXTRAÍDA DE INTERNET}

Centro Virtual Cervantes, consultada el 2 de julio de 2010 en: http:// crc.cervantes.es/ensenanza/biblioteca_ele/diccio_ele/diccionario/contextodiscursivo.htm

FeCha de RECEPCIÓn DEL ARTíCulo: 3 de septiembre de 2010 FECHA DE ACEPTACIÓN Y RECEPCIÓN DE LA VERSIÓN FINAL: 1 de junio de 2011 